\title{
New EEQ S.A. SCADA and Substation Automation Project
}

\author{
Raúl Ruiz R., Senior Member, IEEE
}

\begin{abstract}
This article shows the main characteristics of actual EEQ SCADA System, as well as the most important aspects to be considered within the design requirements of a new SCADA and substations automation according with new technical criteria, the use of international standards and the application of the most modern technological solutions. The relevant concepts applied in a design based on open architecture and the implications of the integration of the IED's within the substations automation are analysed to take advantage of the maximum potentialities and varied functionality of these intelligent equipment. Finally the basic requirements of the communication system for the new SCADA are approached.
\end{abstract}

\section{INTRODUCTION}

The development of computational systems, in hardware and in software, have influenced positively so that it improves the cost-benefit relation in the new Supervision and Data Acquisition Systems - SCADA -, that makes more attractive the processes of modernization of old SCADA systems.

On the other hand, with the advent of new technologies applied to the substations automation, it has been made possible that several functions, previously performed by independent systems and equipment, at the present time are made by intelligent devices, that having ample capacity of processing are able to perform multiple functions. One of the most important aspects in the use of the IED's, in its substation level integration, is to take advantage of corporative information systems as a way to extract the maximum possible benefits in its potentiality of data processing.

This EEQ Project is based on a global development concept for its new SCADA System, substations automation and during a later stage, the expansion of the system towards the automation of distribution networks.

\section{ACTUAL SITUATION}

The Empresa Electrica Quito S.A. offers the electrical service to Quito, capital of Ecuador and Cultural Inheritance of the Humanity, with approximately 600,000 clients located within its concession area.

Raul Ruiz R. works with Empresa Eléctrica Quito S.A., PO Box: 1701-473, Quito-Ecuador, phone (5932) 2227703; e-mail: rruiz@ieee.org

By the end of the $80^{\prime} \mathrm{s}$ was implemented a Pilot DISTRIBUTION LOADS CONTROL and MANAGEMENT Project. This project included the installation of a Control Centre located in the main building of EEQ S.A. and six remote terminals installed in equal number of substations. At the moment it works with a SCADA software package named ILEX 9000 installed in a PENTIUM IBM Netfinity 3000 server, with OS/2 WARP as operating system. By means of a LAN it communicates with two IBM Personal Computer 300GL stations and with a logging printer to register events and alarms.

Later on, the Pilot Project was extended increasing the substations number controlled by the system. At the beginning of 1999, eight ELIOP type ELITEL 4000 remote terminals were bought, with capacity to store collected data in the local data base, capacity to communicate with more than one control centre, using one or several communication protocols.

In summary, present system SCADA is made up of a Control Centre with a simple LAN and two operation stations to control fourteen substations that have remote terminal units (RTU). The communications between the RTU and the master station are made through radio and dedicated telephone lines, as shown in fig. No. 1.

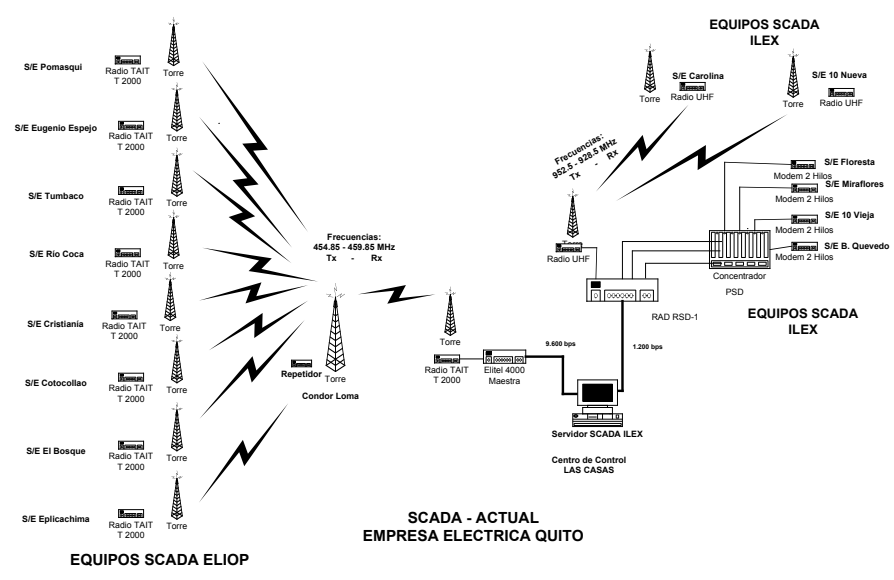

Fig. 1 Actual EEQ SCADA

This SCADA system does not allow any further expansion, because their resources are completely used, so that its change by a new system designed under concepts of open architecture is required.

\section{OBJECTIVES}

The Empresa Electrica Quito S.A. looks for to replace their present SCADA system and the equipment of their Control Centre with a new one that fulfils the requirements of open architecture.

The Control Centre will have to monitor and control 8 existing ELIOP type ELITEL 4000 RTUs and the new RTUs. Also, it will have the capacity to communicate with the new CENACE National Control Centre. 
The main objectives of new SCADA Project are indicated as follows:

1. To obtain a immediate improvement in the indicators of service quality, by means of the drastic reduction of the response times in case of disconnections caused by faults in the sub transmission system, distribution feeders or by external faults to the EEQ electrical system. The present quality indices indicate the fulfilment of the CONELEC (National Advice of Electricity) regulations, but with margins very near the established limits.

2. To start with a process of progressive substation automation. It will, as far as possible, be tried to avoid the use of analog signals wired from the cabins to the RTU in order to reduce the costs of substations internal wiring. For obtaining the required analog variables, microprocessor relays or IED's (Intelligent Electronic Devices) will be used, such that they can communicate to the RTU by means of a serial connection (RS-485) or by means of a substation LAN Ethernet type.

3. To reuse the equipment of present RTUs as far as possible, with the purpose of reducing the costs of investment in the new project.

4. To obtain an integration of the operation of the subtransmission and the distribution system .

5. System SCADA must satisfy the requirements of "Open architecture" in such a way to reach an integration with the other systems or packages of information that EEQ uses, which at the moment work in independent platforms.

The new SCADA System must have a sufficient capacity to allow the future automation of the operation of equipment, like reclosers or switches, installed throughout the primary feeders, to allow future substations growth and expansion and to allow the inclusion of new application functions.

\section{Control Center Configuration}

The Project includes the following components:

\section{Supervision, Control and Data Acquisition (SCADA) System.}

2. Storage and recovery of historical information

3. DMS applications

4. Maintenance and development system.

System SCADA will be based on an operating system adapted for real time data acquisition with standard versions and fulfilling the open architecture requirements. The programs that offer support to the operator as the historical information applications or archives, that have a high requirement of $\mathrm{CPU}$ process time, must be installed in separated computers. The distributed configuration assures a fast answer even in conditions of high load of the system. The accomplishment of the concept of open architecture assures the growth of the system with new functions and the replacement of hardware without causing the interruptions of SCADA System. The man-machine interface must be friendly and offer a fast access to the information required by the operator. The open architecture concept includes:

Portability: it refers about the possibility of using the same software in different hardware/software platforms with the purpose of avoiding the dependency of a specific manufacturer.

Interoperativity: it is the ability to run software modules, being identical ones or not, in different platforms from the same network, at the same time, all communicating and interacting to each other. This is, different hardware of different manufacturers, operating systems and software modules can coexist in a network, all being part of the same SCADA system.

Expansibility: The SCADA software must be able to efficiently allow expansion or growth of the electrical system. The growth of the system and the inclusion of new functions of software must easily be integrated, maintaining the system performance.

Modularity: it is related to the ability to modify the SCADA software with a low impact in the diverse components of software not involved directly in this change. The software modules can be added, be modified, replaced and in many cases extracted without affecting the other modules.

Scalability: it is the ability to use the same software in SCADA systems of different sizes. The same data base is used, the same interfaces, the same software of communications and other support modules of big and small systems.

The Control Centre configuration with its main components can be seen in the following figure:

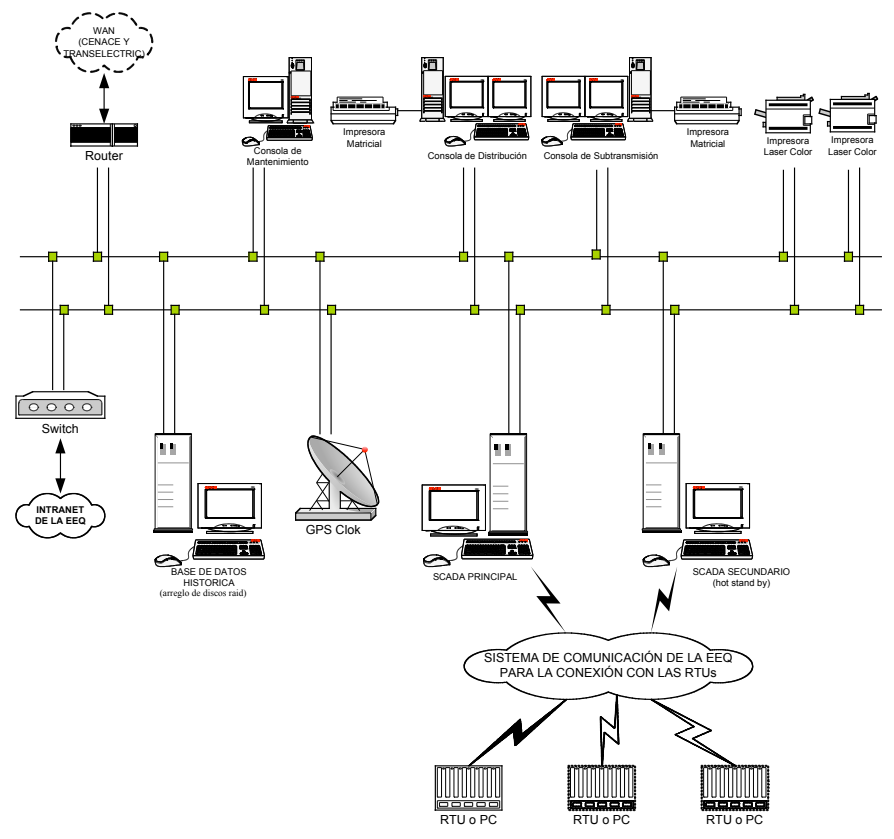

V. SCADA

The SCADA must collect, process and store the data from different sources, like remote terminals (RTUs)/Data Concentrators (CDS's) and IED's located in the different substations from the electrical system, as well as to execute 
the functions of data processing, alarms, sequence of events, time stamped, etc. Therefore, their requirements as far as speed of acquisition and data processing is concerned, are high. Also, the reliability levels (availability) of their components must guarantee their correct operation in normal and emergency electrical system conditions.

The SCADA data base must be available for different users: CENACE Control Centre, Operators, DMS applications and other applications that they require to integrate itself to the SCADA.

\section{A. Historical information}

The historical information system is used to process data, to file them and to later reconstruct them at the moment that is necessary, constituting itself in the main depository of information to all EEQ users.

The ease of use and the system high performance are decisive factors in the total quality of SCADA system, therefore, these functions must be executed in high availability processors.

\section{B. Distribution Management Applications}

The use of computational tools that allow the operator to have a knowledge of the electrical system operation is very important with the purpose of assuring a correct and efficient operation.

The management applications required for the operation of the distribution and subtransmission electrical systems, are the following ones:

- $\quad$ Acquisition and storage of data during a fault or disturbance.

- "Post disturbance" analysis: it allows to control with a "photography" of the electrical system for later analysis of the disturbance.

- Equipment operations storage.

- Reports of disconnections and reliability indices calculation of the electrical system.

- Network state processor.

- State Estimator.

- Load Flow.

The maintenance and development system allows the development and maintenance of the most important components that reflect the state and configuration of the electrical system:

- Electrical system data base.

- Interactive Screens for the operation of the electrical system. The SCADA System must be provided with an initial data base and the necessary tools for the elaboration of the screens, fulfilling the following requirements:

- To be simple to allow a fast entrance of information to the data bases and a fast elaboration of screens.

- To be interactive, with the use of modern methods of user interface graphs that are of generalized acceptance, like for instance the WYSIWYG (what-you-see-is-what-you-get).

- It is provided with development tools of software, like compilers and development programs to facilitate the integration of other computational packages working in EEQ.

Also, the maintenance system have to make the diagnosis and the system management, all this without affecting the functions of real time operation.

\section{RELIABILITY}

The reliability requirements of the system are more easily expressed using the average during the life of the equipment, mean time between failures (MTBF), by the decreasing index at the beginning of the start up, called "infantile mortality" and by the increasing index at the end of the life, call "end life". Based on the indicated terms, the objectives of the design of the system must be:

- $\quad$ The period of "infantile mortality" must be eliminated by the supplier before embarking the equipment in factory.

- $\quad$ The MTBF index is greater or equal to 4000 hours.

- That the "end life" begins at 10 years service.

- That a single fault in hardware or software anywhere of the system does not cause a critical fault.

- That the faults of components do not propagate throughout the system, increasing the damages and loss of functions.

The equipment fault modes and the effects of these faults must be analyzed by the supplier. The results of this analysis (FMEA failure modes and effect analysis) must be available for revision on EEQ, when they were required.

\section{MANTENIBILITY}

The maintenance and the replacement of parts and pieces with fault must be made by personnel trained by the supplier. The supplier must train EEQ personnel, to identify and to replace modules damaged in site, for which it will have to provide a listing of spare parts justified by the analysis of equipment fault mode.

In the calculation of the amounts of spare parts and the time in which it is possible to make them available, the supplier must consider the required time to return a faulted component to its ready operation condition. The spare parts must have a technical guarantee of at least 3 years. The supplier must guarantee the provision of spare parts at least 10 years time period, since the expiration of the equipment guarantee.

The MTTR must be smaller or equal to 24 hours. In order to assure the fulfilment of this parameter, it is necessary to include the following:

- Training and documentation directed towards the maintenance technicians.

- $\quad$ Equipment provided with self-diagnosis, auto tests and procedure of detection of faults. 
- Facility of access to the test terminals and disconnection points.

- Ways to avoid mistaken connections.

- Units, modules and cables correctly identified.

- Warnings to avoid voltages and dangerous conditions.

- Provision of test terminals for input/output simulation equipment.

- Provision of extension cards for card tests and internal circuits.

\section{AVAILABILITY}

Prior the acceptance, the provided system will have to pass the availability test. The guaranteed level of availability must be greater or equal to 2000 continuous hours of operation.

\section{Substation Automation}

The substation automation system is a computacional system that integrates several subsystems that normally operate in independent form such as SCADA, communications, protections, control, measurement, alarms announcers to obtain a unique system of substation data acquisition, monitoring and control.

The substation automation process looks for to obtain the data stored in the IED's in an agile and safe way. The use of IED's has become general for several reasons and among them: to diminish costs of automation and integration, to improve the operation and to improve the service. These intelligent devices have the capacity to make one or several functions like the measurement, protection, control and communication with the RTU or Substation Data Concentrator. Examples of the functions performed by IED's, are the following ones:

Measurement: information acquisition of the most important electrical variables like phase currents, voltages phase-neutral, residual voltage, frequency, power factor, overvoltage, undervoltage, active and reactive power, energy, etc.

Protection: they present a very ample range of protection functions, distance protection, directional and nondirectional overcurrent protection, earth faults protection, residual voltage, over and under voltage, control of synchronism and autoreclosure.

Control: local and remote control functions of several equipment like disconnecting switches, with the state indication.

Condition monitoring: monitoring functions to check the circuit breakers condition and programming the circuit breaker maintenance.

Communications: for SCADA integration is important to have a standard open interface and standard communication protocols like IEC 870-5-103, DNP 3,0 or new IEC 61850 based on UCA 2.0.
The requirements for substation automation design are based on the hierarchic levels detailed in [1] that are indicated in the fig. No. 2. At LEVEL 3 corresponds the interface of communications with the Control Centre, at LEVEL 2 the substation data concentrator CDS or the RTU with the local interface of substation operator and the information storage, at LEVEL 1 corresponds substation LAN, and at LEVEL 0 the associated communication and interface with the IED's or individual input/output points to the substations equipment.

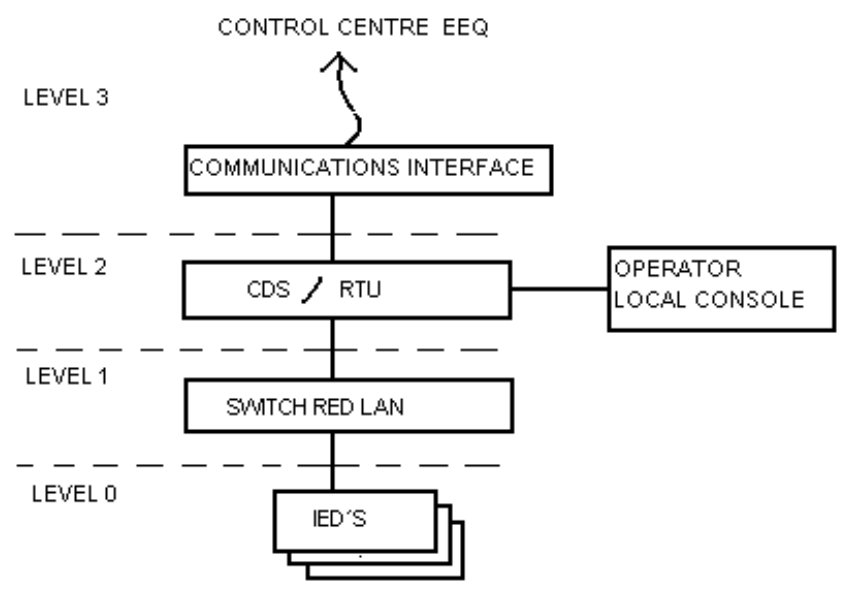

Fig. 2 Substation automation Hierarchic Levels

The design requirements, as far as response times of the system, are: time of maximum delay for protection opening commands $4 \mathrm{msec}$ and data acquisition time for the SCADA 1 to 2 sec.

The CDS/RTU must have the capacity to acquire the analog and digital data in real time, and the notifications of events from the IED's, are through interrogation or another mechanism.

The IED's must have the capacity to report by exception, it transmits only the changes of state and the variations of analog data that exceed the dead band. Also the information from the IED's must be stored in the CDS/RTU data base.

The CDS/RTU must process the information and control orders send from the Control Centre towards the IED's. In addition the CDS/RTU must have the control on the following subjects related to the IED's:

- To know each IED address.

- To know the alternating communication routes with each IED.

- To know which IED can be used to carry out a specific function.

- To know the state of all the IED's connected.

- To synchronize the time of all the IED's connected.

- To have access to the IED's sequence of events storage.

The basic premise in the IED's integration process will be to take advantage of the maximum potentialities offered by the IED's, therefore it will allow to the reception of the analog and digital information from the IED as well as the shipment of the control signals from the RTU to the IED's. 
Also it is very important to have access to the IED's sequence of events storage.

\section{COMmunication System}

The actual EEQ SCADA communications system is made up of a radio system that operates in the band of UHF with frequencies 459,85 and $454,85 \mathrm{MHz}$ for eight substations (Pomasqui, Chillogallo, Tumbaco, Río Coca, Cristianía, Cotocollao, Floresta and Granda Centeno) with ELIOP RTUs and TAIT radios.

Two substations (Carolina and 10 Vieja) that have RTU's ILEX communicate with the Control Centre in 928,5 and 952,5 MHz. Additionally 4 substations connect with dedicated lines (Floresta, Miraflores, El Dorado and Belisario Quevedo), also with RTUs ILEX; this scheme is in Figure No. 1.

\section{Project Communication System}

The project contemplates the acquisition of a new SCADA system with a new Control Centre, new CDS/RTU in the rest of substations and a new communication system. This system will allow the transmission of video and voice communications from the substations.

The physical channels to be used in this communication system of will be: a main trunk of optical fibre and a system of spread spectrum radio or one with OFDM technology. In order to respond to corporative necessities, a main trunk of optical fibre that communicates the main administrative centers was put into operation. This main one will be extended to connect several substations, so that the SCADA system can make use of this connections.

The substations that are not connected by means of the optical fibre will have to connect via radio: Two technically feasible alternatives economic have been considered: the spread spectrum system and the OFDM system.

\section{CONCLUSIONS}

The main design requirements of the new SCADA have been described. It is important to indicate that the bidding documents, in general, contains the functional specifications, leaving the details of the design to the supplier, although it is necessary to indicate that at the moment system requirements of standard open architecture are based on standard equipment. The concepts of open architecture will allow to develop the integration of computational systems within the EEQ. In addition these concepts assure the SCADA operability, the inclusion of new application functions and the evolution towards the automation of the distribution networks.

\section{REFERENCES}

[1] J. McDonald, D. Caceres, S. Borlase, M. Jansen, "Standardized Design of Transmission Substaion Automation Systems", paper presented in XIII Congreso Nacional de Ingenieria Mecánica, Eléctrica y Ramas Afines - CONIMERA, Agosto 1999, Lima Perú.
[2] J. McDonald, Electric Power Substations Engineering, CRC Press, 2003.

[3] Especificaciones Técnicas del Nuevo Sistema SCADA para la EEQ S.A.

[4] SIEMENS Catalog SIP2002 SIPROTEC Numerical Protection Relays.

[5] ABB Buyer's Guide 1999 Station Automation \&Protection 